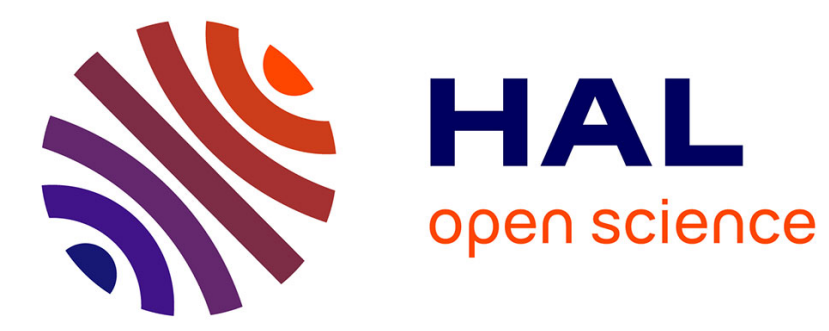

\title{
Work, Innovation and Sustained Development
}

Valérie Pueyo, Pascal Beguin, Francisco Duarte

\section{To cite this version:}

Valérie Pueyo, Pascal Beguin, Francisco Duarte. Work, Innovation and Sustained Development. Advances in Intelligent Systems and Computing, 2019, Proceedings of the 20th Congress of the International Ergonomics Association (IEA 2018), 825, pp.861-869. 10.1007/978-3-319-96068-5_92 . halshs-01961231

\section{HAL Id: halshs-01961231 https://shs.hal.science/halshs-01961231}

Submitted on 15 Jan 2019

HAL is a multi-disciplinary open access archive for the deposit and dissemination of scientific research documents, whether they are published or not. The documents may come from teaching and research institutions in France or abroad, or from public or private research centers.
L'archive ouverte pluridisciplinaire HAL, est destinée au dépôt et à la diffusion de documents scientifiques de niveau recherche, publiés ou non, émanant des établissements d'enseignement et de recherche français ou étrangers, des laboratoires publics ou privés. 


\title{
Work, innovation and sustained development
}

\author{
Pueyo Valérie ${ }^{1}$ Pascal Béguin ${ }^{1}$ Francisco Duarte ${ }^{2}$ \\ ${ }^{1}$ University of Lyon, UMR 3600 EVS, France \\ ${ }^{2}$ University Federal of Rio de Janeiro, COPPE, Brasil \\ valerie.pueyo@gmail.com, pascal.daniel.beguin@gmail.com, \\ fjcmduarte@gmail.com
}

\begin{abstract}
There is an agreement to consider human work as being insufficiently considered in the challenges set by Sustainable Development. This communication discusses why work is a "forgotten dimension" of sustainable development. We suggest (i) the interest for a greater attention to the relationship between work, technique and activity, (ii) the necessity to articulate on the one hand the design of innovative technologies and on the other hand the question of living together at work, and (iii) the need, given the depth of changes required on work activity during transitions to sustainable development, to pay attention to the experience of the workers.
\end{abstract}

Keywords: Work, activity, innovation, technique, living together at work, experience.

\section{Introduction}

Work is commonly considered a forgotten variable in sustainable development [1]. How can we remedy this, and how can we give work a place in the transition to sustainable development?

The goal of this text is to provide a provisional list of all of the research that we have carried out to reflect on innovation strategies facilitating the transition to more sustainable production methods. As ergonomists, our goal was to work towards fully integrating the work of today and of the future into these strategies, both in terms of concepts and methods, not only on the level of the technical variables of innovation, but also that of the normative dimensions of working conditions.

We will first explain why it is valid to consider work a minor or even hidden dimension of sustainable development. It is undoubtedly possible to find evidence of issues relating to work in the social equality pillar of the latter, which along with its economic and environmental pillars have been structuring sustainable development issues since the Brundtland Report [2]. Nonetheless, we believe that it is also necessary to focus on the existing relationships between work, technology, and activity in order to make a place for work. 
Subsequently, we will argue that these relationships must be understood from two angles. The first is regarding technology and innovation (and questions the actionability of technology at work and the impact of work on innovation pathways). The second is regarding the sustainability of work (and aims at identifying innovation processes focusing on sustaining work, perceived from the angle of social insertion or working conditions). Based on a comparison of these two angles, we will show that the social does not exclusively stem from the normative, and that innovation does not exclusively stem from technology. These two dimensions - the technical and the political - are inexorably intertwined, and must therefore be addressed simultaneously in order to transition to more sustainable production methods. On the other hand, we will show that the depth of the changes triggered leads to analysing and giving a central place to the experience of work both on the conceptual and methodological levels.

\section{Work in the context of sustainable development: a hard labour to be mitigated, or a resource to be developed?}

If we carry out a comparative analysis of the place allocated to work into its conceptualization in sustainable development [3], it is possible to observe i) that it does not constitute a priority component of the latter and ii) that its consideration primarily relates to exertion, but that iii) considering work a resource constitutes a concern.

Without going over the complex history of the emergence of the concept of sustainable development, it is necessary to state that since its beginnings in the 1960s up until the Bruntland Report (1987), which henceforth marked its common global form, we find no (or very little) trace of work. What predominates in the debates are primarily the tensions between the economic and environmental dimensions [4]. In this sense, while the Bruntland report presents sustainable development as a structure composed of three pillars - the environment, the economy, and social equality, in which work has a place -, these are by no means equivalent.

Moreover, if we examine the social equality pillar, it is not so much work but rather employment or the right to work that it discusses. Effectively, access to employment and insertion by means of employment constitute major points of concern. After that, priority goes to the rights conferred by work in the form of fundamental labour standards [5] [6]. These standards guarantee access to a productive and decent job, i.e., one that has i) fair compensation, ii) safe conditions at the workplace, iii) social protection covering the risks of occupational disease and accidents related to the work, and more recently, iv) devices enabling social dialogue. Therefore, it is not surprising to observe that what is analysed and implemented essentially consists of designing and overseeing international labour laws: the Fundamental Conventions of the ILO, freedom to unionize, the right to organize and participate in collective 
bargaining, forced labour, the minimum working age and child labour, equal compensation, discrimination, governance agreements, workplace inspections, tripartite consultations, or employment policies. In this pillar, the work component is fundamentally situated on the normative level and in terms of dimensions relating to working conditions. Ultimately, it is anchored in a viewpoint in which work is understood in terms of the aspect of exertion and hard labour. In short, it is likened to a field of constraints that must be regulated and normatively controlled in order to sustain it.

Nonetheless, a few recent publications have shifted this frame by seeking to understand work not as exertion but as active participation in the world and as a creative contribution allowing humans to join a community and create a viable future with it [7]. These publications follow the viewpoint of ergonomists, for whom work, understood as an activity with a purpose in itself, plays a role in the fulfilment of human beings. In this context, work is a valuable "resource" in transitioning to sustainable development.

This is the viewpoint that we follow. When understood as a resource, work goes hand-in-hand with the need to consider work that is truly human for the world to function. Because of this, we believe that it is very important to i) better elucidate the relationships that exist between work and sustainable development from this angle and on the level of activity, and ii) to put work back at the heart of the actions carried out if we wish for the transition to sustainable development to take place in a way that benefits human beings.

\section{Work, technology, innovation and sustainable development}

At the workplace, the transition to sustainable development takes place through the implementation of innovation strategies, or at the very least by seeking them out. These strategies, which are granted a place in design projects, are massively based on technical dimensions. How is it possible to explain this centration? How can focusing on the elements in play in these projects from the angle of technology constitute an opportunity to give work a place? Two dimensions must be taken into account in this sense.

From the viewpoint of sustainable development, economic viability must be rationally justified. Economic development cannot continue to rely on the belief that on one hand, resources are supposedly infinite and inexhaustible, and on the other hand, growth is automatically a factor in progress. It is in this context that technology appears to be a major adjustment variable. It allows to find new ways of producing, but also new products allowing to preserve the environment and resources (including human beings). In this case, the goal is to design efficient systems with a reduced environmental impact. In this sense, the words of Hubert and Godard [4] come to 
mind: technical decisions are key variables in harmonizing the social and environmental spheres. Moreover, this strategy concerns all industries, from agriculture to energy, from green business to urban planning (construction, transportation, etc.). However, is this truly the case? And in the case of ergonomics, do technical decisions and the design of artefacts (whether physical or cognitive) integrate issues relating to work and the activity of actors?

The second dimension is directly related to the way of conceiving of what constitutes work. Above, we mention research that seeks to liken work more to a resource than to a form of exertion. Among these publications, we can cite research on the concept of decent work [8]. In it, work is considered to have two dimensions: subjective dimensions relating to the meaning of the work for individuals, and objective dimensions relating to that which is produced by the work and its purpose. Yet, this second dimension directly refers to how technology and efficient know-how act on the world. The needs of populations, in their possibilities of achieving "human mastery of the universe", constitute its boundaries. In its objective dimension, work is therefore indissociably tied to the technical and the execution of action - the technical being understood as efficient know-how and the creativity to act on it, simultaneously integrating both that which is and that which could be, that which exists and that which is possible. Seen from this angle, technology makes it possible to give an entirely different place to work. It is no longer exclusively exertion or hard labour, but also a way of acting on the surroundings and a creative production.

Focusing on technology - not only on the level of technical objects but also on the level of "efficient" and creative action - has three advantages:

- The first, as we just mentioned, is that work and activity are perceived differently from this angle, and by doing so, a legitimate place is granted to key players in projects.

- The second is that by being related to action and doing, technology pertains to a desire to transform the surrounding environment from the outset.

- The third is that technology, in view of this transformation, simultaneously highlights the opposing elements of that which is - the existing, resources and that which could be.

This centration on technology thus constitutes a field of opportunities given that work can find a place in it, all the while following with a strategy that is widely followed outside of ergonomics.

However, this centration undoubtedly raises a set of challenges. In reality, it is by no means obvious that technology can constitute a vector in harmonizing social and environmental variables. For ergonomics especially, such an approach raises the question of the deep-seated difficulties that actors may face with respect to innovation, both on the level of changes in work systems as well as the level of professional transitions; enabling, for example, farmers to leave behind intensive production methods to instead switch to production methods that are more respectful 
of the environment. What processes must be implemented to accompany such changes, and what design process allows to support/sustain these [9]?

\section{$4 \quad$ Technological innovation and sustaining work}

We have presented two different angles: that of sustaining work, in which the latter is understood as hard labour and exertion that must be regulated legislatively; and that of technical innovation, which raises questions around the execution of action.

We sought to examine the elements in play in these very different configurations of the transition to sustainable development, on one hand from the angle of addressing different (yet complimentary) facets, and on the other hand from the angle of reflecting on the diversity of possible pathways on the level of strategies and processes.

The first configuration stems from projects in which technical innovation strategies play a role; it closely follows with what we have just mentioned. The second refers to innovation processes that focus not on the variable of technology but on sustaining work.

\subsection{Steering technical innovation}

This configuration takes place in the form of innovation strategies focused on technology, and essentially aims at designing efficient products and systems that reduce environmental impacts. Two issues emerge from this: the first concerns the actionability of the techniques designed on the level of work, while the second concerns the impact of work on innovation pathways. A brief example will demonstrate why it is necessary to integrate these two questions during a project.

This example is from the energy sector [10]. The goal was to implement "smart meters" that would allow the power company to act on flows. This regulation made it possible to establish reserves, but also to decrease and adapt energy production and consumption. Consequently, the goal was to contribute to decreasing environmental pressure. In order to better understand i) the equipment that could play a role in smoothing out of flows and ii) the most suitable periods for doing so, an experiment was launched. It consisted of installing a measurement system that would allow to carry out an assessment at two pilot sites at the premises of private customers and business customers (industrial environments, service environments, local governments, etc.). However, numerous problems arose. Connecting meters to equipment (air conditioning units, manufacturing machinery, etc.) was not so simple. It required a specific installation and was based on the interoperability of equipment (in other words, the possibility of pieces of equipment communicating with one another). Moreover, this required programming various pieces of equipment when 
possible. It was then necessary to ensure that meters could be installed in a way suitable for integrating them. Last of all, the data that they recorded had to be comprehensible and interpretable. However, for the agents carrying out the maintenance of this equipment at the pilot sites, ensuring interoperability was not within the scope of their capabilities. Programmer and integrator capabilities were necessary, but these professions were not yet widespread. Even though they were present at the companies, the criterion governing their work was based on the energy management of buildings, but this was not what presided over the smoothing out of energy flows. During this experimentation phase, the project team thus discovered that the problem was not the technical object (the meter). Rather, the problem was its actionability at the workplace, due to it being out of phase with the state of existing technical facilities and the implementation requirements in order to enable it to be used (e.g. interoperability, installation) on the level capabilities as well as a variety of criteria and action logics - such as building energy management. To overcome this problem, the project team hired a power engineer. He was responsible for integrating the criteria relating to the characteristics of the building, among others. On the other hand, the team also organized to examine the different "lock-ins" emerging on the technical, economic, and organizational levels, such as the absence of programmers and integrators.

In addition to the issue of actionability as just mentioned, the issue of the impact of work on innovation pathways also comes up. In our example, work led to transitioning from an innovation strategy focused on the meter to an innovation strategy focused on a service. As we have just seen, the experiment conducted enabled the discovery of multiple lock-ins. In order to overcome them, the project group i) acknowledged the change in work object, ii) integrated the need for new capabilities (those of integrators-programmers and power engineers), and above all iii) shifted from an experiment aiming at validating a concept (proof-of-concept) to a redesign process engaged in a dialogue with pilot sites. All of this stemmed from the change in the object to design and therefore the work object. The process no longer consisted of specifying the pieces of equipment and period suitable for using the meter, but of achieving energy efficiency. To do so, it became apparent that it was necessary to interrelate the assessment of the features, performance, and energy resources of the building (insulation, situation, etc.) and the features of the equipment (programming language compatibility, for example) with work uses. Moreover, in doing so, it was necessary to analyse the resources necessary (on the technical, organizational, and capability levels, among others). It was an approach enabling this type of integration on the technical, temporal, and human levels that constituted the service offering. Therefore, it was the integration of the realities and needs of sites, and in particular the realities of the work and the professions present, which required them to be articulated around a new object - mastering energy efficiency -, thus impacting the innovation pathway. Moreover, this new object also required new work methods (in interrelation and cooperation with each other), along with renewed resources and a need to make existing career practices evolve, or even the need for the 
emergence of new careers at the intersection between these elements, careers that have caused this pathway to shift.

\subsection{Taking the sustainability of work into account}

As we stated above, because work has largely been situated in the social equity pillar, the projects implemented in view of transitioning to sustainable development often focus on sustaining work. This need to sustain it stems from two issues: on one hand is social insertion; on the other hand are safe, non-deleterious, and non-excluding working conditions. Nonetheless, it appears that accompanying the sustainability of work can under no circumstances be dissociated from technical issues. A project carried out in the mining sector in Brazil gives an example of this [11].

This sector is faced with major problems on the level sustainability, including serious workplace accidents, arduous working conditions, and a high occurrence of lung disease related to exposure to silica dust. This observation led to the creation of a standard: work had to be carried out in zero-dust environments, using rock humidification procedures to neutralize dust production when cutting. The entry of this component into projects and discussions was therefore normative and political. It was a requirement accompanied by a technical obligation, without, however providing instructions regarding the path to follow or the procedures to use. The urgency was above all to protect workers. However, at mining companies, the response to this requirement took place through seeking technical devices allowing to work in a dust-free environment. This search took several years, and included the outfitting of the hammers and picks used to break granite by inserting protective cuffs on them, the implementation of properly-adapted water sources, and experimentation with and the redesign of a hydraulic drilling machine integrating the water requirement. The technical component was therefore very present in this configuration.

Beyond that, these experiments guided by legislation and crystallized around technology were a chance to discover certain hitherto unthought of dimensions of the work and work systems: these included problems with the quality of boring and the need to collect information during this operation; problems with coordinated work (considering that blocks of granite are separated into multiple segments on which multiple labourers work simultaneously) and the spaces associated with this collective dimension; problems with the accuracy and power to develop for the tool modified by devices; problems with maintenance, times, and costs, since drill bits would get stuck during boring due to the water and heat up, requiring them to be changed. During the testing, the dimensions constituting the work system on the micro as well as meso level (e.g. the organization of teams, the work time, the organization of maintenance...) emerged, and each difficulty was an occasion to unveil them, to such an extent that each solution found to overcome a challenge would be the occasion for a "systemic propagation"; in other words, the resolution of one aspect raised questions around another. This propagation would ultimately lead to dust-free work in 
conditions more favourable to health, all the while maintaining production and quality objectives. However, it was only made possible by the implementation of projects combining a large number of prevention actors as well as engineers, technicians, and labourers in a "step-by-step" manner, i.e., by going back and forth between technical and organizational decisions and concrete experimentation at the site. This also triggered very profound transformations in ways of managing job sites, but also in the professional practices of key actors. For example, labourers came to implement new jobsite coordination choreographies, and developed other indicators and criteria for working with rock and drilling into it, other capabilities for maintaining tools, etc.

From our viewpoint, comparing these two configurations leads to two important reflections, both on the conceptual and methodological level, for placing work at the centre of initiatives.

\section{The overlap between the politis and the technical, and the experience of work}

Our first reflection is regarding overlap between the politis (i.e. the normative dimensions of living together) and the technical [12].

In technical innovation projects, the focus is essentially placed on the descriptive and analytical category specific to technology. On the contrary, innovation approaches that focus on sustaining work place emphasis on the normative dimensions related to coexistence (achieving economic objectives without having a negative effect on workers' health). Nonetheless, the two examples mentioned demonstrate that the technical and the political are closely intertwined, and must be considered an inseparable whole:

- In the first example (energy efficiency), it is possible to measure to what extent the project, by integrating the change in object and the realities of the existing and desired resources, was based on political dimensions. This is true in two ways. The first is relative to defining a new goal to achieve (mastering energy efficiency). New criteria appeared at the time (the building and the uses associated with it in relation to the work and equipment), raising the question of the values associated with the actions carried out and their interrelation with one another within a professional community. These are points that constitute new collective standards that define a framework for coexistence at work. This touches on the normative power ofdesign during the creation of techniques and innovative projects. The second way resides in the fact that such a project, by accepting the reallife challenges encountered by its purveyors, re-analyses its relationships to others during design. Effectively, focusing on the technical variables of a meter or on the uses of the building is not equivalent from the point of view of the place granted to actors at the pilot sites. By interrelating energy production and use, the project raised the question of the overlap between the 
perspectives, viewpoints, and criteria mobilized around a single object. The goal was thus to carry out a joint undertaking, to contemplate collective action, and to execute it together.

- In parallel, the second example (decreasing dust in mines) shows that in a configuration in which the normative takes precedence, the technical variable resurges. This is because the requirements of sustaining work must draw support from concrete dimensions that serve as a framework for executing action. To do so, innovative techniques are required. Once again, under the condition that a place is given to the reality of the work and the elements obstructing it, techniques appear to be a point of support for articulating perspectives, exploring new paths, and ultimately redefining the spaces, modalities, and criteria of coexistence.

Our second reflection is regarding the depth of the changes triggered during the transition to sustainable development [13] and regarding the construction of the experience of work [14]. Whether in the context of innovative projects presented as such - i.e., those placed outside of the available technical, cognitive, and social frameworks from the outset -, or sustained work configurations, the purpose of the project and the nature of the work to carry out are profoundly shifted.

In both cases, the scopes of actions, the resources to mobilize, the criteria followed, and in short, the work system in its entirety, must be reconfigured. This is because considerable evolutions are required on the level of activities to be successful. Key actors must learn: either their capabilities evolve, as in the mining sector, or the developments do. Therefore, frameworks for action and thought must be redefined as in the energy efficiency example. What was previously valid and effective for conveying the world and acting upon it is no longer relevant: something different must be constructed. In both cases, these projects raise the question of constructing the experience of work, its evolution, and its reconfiguration.

Therefore, in all cases (whether that of the durability of work or that of addressing the issues of the transition to sustainable production methods), constructing the experience of work (its meaning, its values, its resources, and its purposes), is a central question, along with the project management mechanisms that allow to sustain it.

\section{References}

1. Bazillier, R. : Le travail, grand oublié du développement durable. Le Cavalier Bleu, Paris (2011).

2. Commission Mondiale sur l'Environnement et le Développement. : Our Common Future. Report, dir. Gro Harlem Brundtland, ONU (1987).

3. Duarte, F., Béguin, P., Pueyo, V., Lima, F.: Work activities within Sustainable development. Work 41(1), 89-94 (2012). 
4. Godard, O., Hubert, B.: Le développement durable et la recherche scientifique à l'INRA. Rapport à Mme la Directrice générale de l'INRA. 23 Décembre 2002, (2002).

5. Drouin, RC, Duplessis, I.: La régulation internationale du travail de 1998 à 2008 : un Eldorado normatif ou un désert interprétatif ? » Lex Electronica 14 (2) (Automne / Fall 2009).

6. Déclaration de l'OIT relative aux Principes et Droits Fondamentaux au travail et son suivi,adoptée à la Conférence Internationale du Travail, 86 ème session, Genève (1998)

7. Somavia, J.: Un travail decent. Rapport du Directeur Général à la Conférence Internationale du Travail, $87 \mathrm{e}$ session, Genève, 1999.

8. Egger, P., Sengenberger, W.: Decent work pilot Programme. ILO, Genève (2001).

9. Duarte, F., Béguin, P., Pueyo, V., Lima, F.: Work activity within sustained development. Production, 25(2), 257-265, abr./jun. 2015 http://dx.doi.org/10.1590/0103-6513.156013, (2015).

10. Rosier, A., Gotteland, C., Béguin, P., Pueyo, V.: Analysing professional transitions underway in an experimental project on energy efficiency. In: Proceedings $19^{\text {th }}$ Triennial Congress of the IEA, Melbourne 9-14 August 2015. ATWAD, Melbourne (2015).

11. Mendes, RWB, Pueyo, V., Béguin P., Duarte F.: Innovation, Systemic Appropriation and Prevention in the granite mining sector: the case of humidification. Work 57(3), 351-361 (DOI: 10.3233/WOR-172566) (2017).

12. Béguin, P., Pueyo, V.: Quelle place au travail des agriculteurs dans la fabrication d'une agriculture durable ? Pistes 13(1). DOI : 10.4000/pistes.1708, (2011).

13. Béguin, P.: Développement durable et transition du travail. In : Actes du $52^{\text {ème }}$ Congrès SELF « Présent et Futur de L'Ergonomie : Répondre aux défis actuels et être acteur des évolutions de demain ». 20-22 Septembre 2017, pp. 699-701. Self, Toulouse (2017).

14. Béguin, P., Lima, F., Pueyo, V.: De l'appropriation des inventions à l'appropriation des processus d'innovation. Questions sur la place de l'expérience. In : Actes du 50ème Congrès SELF «Articulation performance et santé dans l'évolution des systèmes de production », pp. 463-467. Self, Paris (2015). 